Published in: Composite Structures

Accepted: 9 January 2020

DOI: https://doi.org/10.1016/j.compstruct.2020.111916

\title{
Strength Enhancement of Bonded Composite Laminate Joints Reinforced by Composite Pins
}

\author{
Wenhao Li, Shijun Guo*, Ioannis K. Giannopoulos, Shun He, Yiding Liu
}

Centre of Aeronautics, School of Aerospace. Transport and Manufacturing, Cranfield University, Cranfield, MK43 0AL, UK

\begin{abstract}
This paper presents an experimental and numerical investigation in the static strength enhancement of composite laminate Single Lap bonded Joints (SLJ), reinforced by pins made of Uni-Directional (UD) fibre reinforced plastic composite materials. Bonded lap joint specimens were experimentally tested in tension to obtain the failure loads and failure modes. The specimens were subsequently benchmarked against the hybrid version of the joint resulted from the introduction of composite Pins. The Pin reinforcement enhanced the hybrid single lap joint strength by an average of $19.1 \%$ increase. Numerical models generated were used for correlation with the experimental results. Numerical and experimental results observation indicated that increased strength of the hybrid bonded/Pinned joint was partly attributed to the load sharing between the adhesive and the Pin past the adhesive failure initiation as well as to the enhanced out-of-plane bending stiffness after the Pin introduction on the lap joint. Numerical investigations were performed as well with hybrid SLJ reinforced by composite pins versus designs employing metallic Pins. The simulations showed that for the investigated lap joint design parameters, the hybrid metallic pin joint failed at a higher failure load. Nevertheless, the hybrid joint utilizing the composite Pin could benefit from the enhanced corrosion resistance properties. In the case of applying a larger composite Pin diameter and/or rearranging the fibre orientation in the Pin, the hybrid SLJs could potentially achieve higher strength characteristics before the adhesive bond ultimate failure in relation to the steel Pin, as well as resulting to additional weight saving up to $46.9 \%$.
\end{abstract}

Keywords: Composite Pin, Bonded Joint, Delamination, Hybrid Joint

*Corresponding author

Email: s.guo@cranfield.ac.uk; Tel: +44 (0) 1234754628 


\section{Introduction}

Composite materials have been extensively used for the design of lightweight structures and structural components across a variety of industrial products, seeking to benefit from the material's superior structural performance and higher specific mechanical properties. Structural components made of composite materials can be assembled together using bolts. Adhesive bonding is a widespread structural joining technique as well. In various industrial applications and for structural component assemblies that play a detrimental role in human safety, using bolted joints or adding mechanical fasteners on top of adhesively bonded joints is considered to be an adequate reinforcement for meeting the required structural performance criteria [1], [2]. The application of fasteners on a bonded joint can delay the bonding failure and can provide with an alternative load carrying, fail safe path.

Conventional fasteners used for joining composite structures are mostly made of metallic materials. Metallic fasteners add weight on the assembled composite structure and prohibit the structural designs from reaching their potential performance levels [3]. Another drawback in the usage of metallic fasteners in general, is galvanic corrosion. Titanium fasteners are favoured in that regard, due to their lower density compared to steel fasteners and the smaller difference in the galvanic potential with the carbon fibre composite structure, compared to aluminium for example. However, using titanium fasteners come at the expense of a higher material cost [4].

A number of studies on composite laminate hybrid bonded/bolted joints available in the public domain, investigated the influence of fastener geometry, material properties and fastener system on the hybrid joint mechanical performance [5]-[10]. Starikov and Schön, carried out an experimental study of composite bolted joints with composite and metallic fasteners, subjected to quasi-static and fatigue loading [11], [12]. Recently, a light-weight and anticorrosion fibre reinforced thermoplastic fastener was manufactured and tested as an alternative to metallic fastener [13]. In that study, three types of the composite fastener with carbon fibre volume fraction of 30,50 , and $60 \%$ were manufactured. The results showed the bolted joint strength increased with the increase of fibre volume fraction in the fastener material, which had higher specific joint strength in comparison to similar joints with metallic fasteners. 
The current study aimed at experimentally and numerically investigating the benefits arising from the usage of Fibre Reinforced Plastic (FRP) Pins on hybrid bonded/Pinned joints with the scope of enhancing the overall joint strength as well as the joint's corrosion resistance. The herein proposed hybrid joint design does not offer the fail safety features that conventional metallic or other fasteners do. The proposed design is not utilizing the Pin as a secondary load path in the case the adhesive bond fails. The application of the FRP Pins on the already bonded joints is enhancing the bonded joint strength during the post-adhesive failure initiation phase. Hence, the strength enhancement of the proposed design cannot be directly benchmarked against more traditional bonded/bolted joint designs using metallic bolts, which tend to retain the lap plate clamping force generated by the bolt under the secondary bending experienced in single lap joints and retain the shear load transfer between the lap plates. There are specific features to this hybrid bonded/Pinned joint that could be regarded as advantageous, depending on the application; the Pin can be installed "flushed" by simple hole drilling and provide with a smooth surface from both sides of the joint as well as it may not require having assembly access from both sides of the joint.

In the following experimental survey, accompanied with various numerical analyses studies, the bearing behaviour of FRP Pins made of Uni-Directional (UD) carbon fibre in epoxy matrix subjected to tensile loading is investigated, along with the strength enhancing effects when applied upon adhesively bonded woven fabric Carbon Fibre Reinforced Plastic (CFRP) laminates. Non-linear progressive damage Finite Element numerical Models (FEM) of the adhesively bonded and hybrid joints were validated by testing. Following FE model validation, various numerical parametric analyses indicated the applicable design space for the hybrid joint.

\section{Material degradation model}

The damage modelling in composite structure can be studied into two categories: (i) intralaminar damage, i.e. fibre tensile and compressive breakage, matrix tensile and compressive cracking, (ii) inter-lamina damage, i.e. delamination failure between neighbouring plies and interface cracking failure. The continuum damage model (CDM) implemented in this study consider both inter- and intra-damage model to take account all possible damage behaviours occur in composites Pin and composite adherents under tensile loading 


\subsection{Intra-lamina damage}

\subsubsection{Damaged material response}

The three-dimensional CDM were employed in modelling of damage progression through introduction of full damage effect tensor [14], [15] based on effective stress-strain theory. The constitutive relation of composite material associated with damage variable $d_{i}$ is updated once the failure criterion initiated [16], which can be expressed as,

$$
\left[\begin{array}{l}
\sigma_{11} \\
\sigma_{22} \\
\sigma_{33} \\
\sigma_{12} \\
\sigma_{23} \\
\sigma_{31}
\end{array}\right]=\left[\begin{array}{cccccc}
\left(1-d_{f}\right) C_{11} & \left(1-d_{f}\right)\left(1-d_{m}\right) C_{12} & \left(1-d_{f}\right) C_{13} & 0 & 0 & 0 \\
\left(1-d_{f}\right)\left(1-d_{m}\right) C_{12} & \left(1-d_{m}\right) C_{22} & \left(1-d_{m}\right) C_{23} & 0 & 0 & 0 \\
\left(1-d_{f}\right) C_{13} & \left(1-d_{m}\right) C_{23} & C_{33} & 0 & 0 & 0 \\
0 & 0 & 0 & \left(1-d_{f}\right)\left(1-d_{m}\right) C_{44} & 0 & 0 \\
0 & 0 & 0 & 0 & \left(1-d_{m}\right) C_{55} & 0 \\
0 & 0 & 0 & 0 & 0 & \left(1-d_{f}\right) C_{66}
\end{array}\right]\left[\begin{array}{l}
\varepsilon_{11} \\
\varepsilon_{22} \\
\varepsilon_{33} \\
\varepsilon_{12} \\
\varepsilon_{23} \\
\varepsilon_{31}
\end{array}\right]
$$

$$
\begin{gathered}
C_{11}=E_{11}\left(1-v_{23} v_{32}\right) \Delta \\
C_{22}=E_{22}\left(1-v_{13} v_{31}\right) \Delta \\
C_{33}=E_{33}\left(1-v_{12} v_{21}\right) \Delta \\
C_{12}=E_{11}\left(v_{21}+v_{31} v_{23}\right) \Delta \\
C_{23}=E_{22}\left(v_{32}+v_{12} v_{31}\right) \Delta \\
C_{13}=E_{11}\left(v_{31}+v_{21} v_{32}\right) \Delta \\
C_{44}=2 G_{12}, C_{55}=2 G_{23}, C_{66}=2 G_{31} \\
\Delta=1 /\left(1-v_{12} v_{21}-v_{23} v_{32}-v_{13} v_{31}-2 v_{21} v_{32} v_{13}\right)
\end{gathered}
$$

Where $\sigma_{i j}$ and $\varepsilon_{i j}$ represent stress and strain tensor, $C_{i j}$ is the matrix tensor consisted of modulus $E_{i j}, G_{i j}$, and Poisson's rations $v_{i j}$. The damage variable $d_{f}$ represents for fibre failure and $d_{m}$ represents for matrix failure.

\subsubsection{Three-dimensional Hashin damage initiation criterion}

3D Hashin damage criteria [17] is used for predicting failure initiation. In each damage mode, the failure initiation is controlled by the component of stress tensor separately, expressed as, Fibre failure in tension $\left(\sigma_{11} \geq 0\right)$ : 


$$
F_{f t}=\left(\frac{\sigma_{11}}{X_{t}}\right)^{2}+\frac{\sigma_{12}^{2}+\sigma_{13}^{2}}{S^{2}}=1
$$

Fibre failure in compression $\left(\sigma_{11}<0\right)$ :

$$
F_{f c}=\left(\frac{\sigma_{11}}{X_{c}}\right)^{2}=1
$$

Matrix cracking failure in tension $\left(\sigma_{22}+\sigma_{33} \geq 0\right)$ :

$$
F_{m t}=\left(\frac{\sigma_{22}+\sigma_{33}}{Y_{t}}\right)^{2}+\frac{\sigma_{23}^{2}+\sigma_{12}^{2}+\sigma_{13}^{2}-\sigma_{22} \sigma_{33}}{S^{2}}=1
$$

Matrix cracking failure in compression $\left(\sigma_{22}+\sigma_{33}<0\right)$ :

$$
F_{m c}=\left[\left(\frac{Y_{c}}{2 S}\right)^{2}-1\right] \frac{\sigma_{22}+\sigma_{33}}{Y_{c}}+\frac{\sigma_{12}^{2}+\sigma_{13}^{2}+\sigma_{23}^{2}}{S^{2}}+\frac{\sigma_{22}^{2}+\sigma_{33}^{2}}{2 S^{2}}=1
$$

Where $X_{t}$ denotes the tensile strengths in the fibre direction, $X_{c}$ denotes the compressive strengths in the fiber direction, $Y_{t}$ denotes the tensile strengths in the transverse direction, $Y_{c}$ denotes the compressive strengths in the transverse direction, $S$ denotes the shear strengths of the composite,

\subsubsection{Damage evolution law}

After failure is predicted using the above criterion, damage variables $d_{f}$ and $d_{m}$, are defined to degrade the stress components linearly from the point of initiation, $\varepsilon_{0}^{i}$, to final failure, $\varepsilon_{f}^{i}(i=$ $c, t)$. For each failure mode, the damage variables $\left(d_{f i}\right.$ and $\left.d_{m i}\right)$ are defined as 0 at onset of failure and value of 1 at final failure, producing linear softening in the effective stress and effective strain space shown in figure 1 [18]. The damage variable $d_{f t}$ and $d_{f c}$ correspond to fibre tensile and compression failure, the damage variable $d_{m t}$ and $d_{m c}$ correspond to matrix tensile and compression failure.

For fibre failure mode, the damage variable $d_{f}$ is obtained by,

$$
d_{f}=1-\left(1-d_{f t}\right)\left(1-d_{f c}\right)
$$

Where 


$$
d_{f i}=\frac{\varepsilon_{f, 1}^{i}}{\varepsilon_{f, 1}^{i}-\varepsilon_{0,1}^{i}}\left(1-\frac{\varepsilon_{0,1}^{i}}{\varepsilon_{11}}\right) \quad(i=c, t)
$$

$\varepsilon_{0,1}^{i}$ correspond to the critical tensile and compressive strains when the damage initiates. The maximum failure strain $\varepsilon_{f, 1}^{i}$ is derived from the fracture toughness of the fibre matrix, $G_{c}$, associated with failure mode and failure strength, $X_{i}$, and the characteristic length, $l^{*}$, which would keep a constant energy release rate per unite area of crack and alleviate mesh dependency problem of CDM [19], [20].

$$
\varepsilon_{f, 1}^{i}=\frac{2 G_{I}^{i}}{X_{i} l^{*}}(i=c, t)
$$

Similarly, for matrix failure mode, the damage variable $d_{m}$ is obtained by,

$$
\begin{gathered}
d_{m}=1-\left(1-d_{m t}\right)\left(1-d_{m c}\right) \\
d_{m i}=\frac{\varepsilon_{m, 2}^{i}}{\varepsilon_{m, 2}^{i}-\varepsilon_{0,2}^{i}}\left(1-\frac{\varepsilon_{0,2}^{i}}{\varepsilon_{22}}\right)(i=c, t) \\
\varepsilon_{m, 2}^{i}=\frac{2 G_{I I}^{i}}{Y_{i} l^{*}}(i=c, t)
\end{gathered}
$$

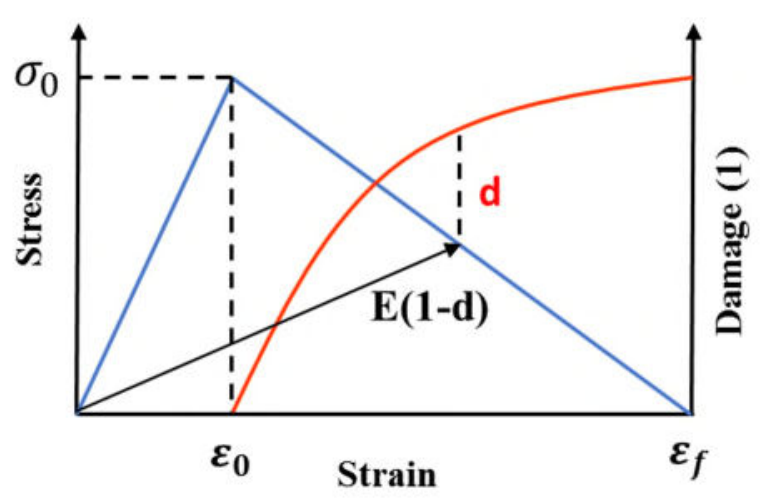

Figure 1. Damage evolution law

\subsection{Inter-lamina damage}

Cohesive Zone Model (CZM) interfaces were used for the a) in-between the plies delamination and b) the adhesive bonding layer, to account for delamination and interfacial cracking. Cohesive damage initiation was triggered by a quadratic nominal stress criterion. 
Cohesive damage propagation was controlled through a bilinear traction separation law based on the Benzeggagh-Kenane (BK) mixed-mode damage evolution criterion [21].

\section{The structural behaviour of the CFRP Pin in shear}

The Pins were made of epoxy thermosetting matrix, reinforced with UD carbon fibres, as produced by Easy Composites Ltd UK in the form of $1 \mathrm{~m}$ long rods in $5 \mathrm{~mm}$ diameter. The UD composite rods were cut into smaller lengths using a diamond saw as shown in figure 2 (a) along with microscopic images of the Pin cross-section as shown in figure 2 (b).
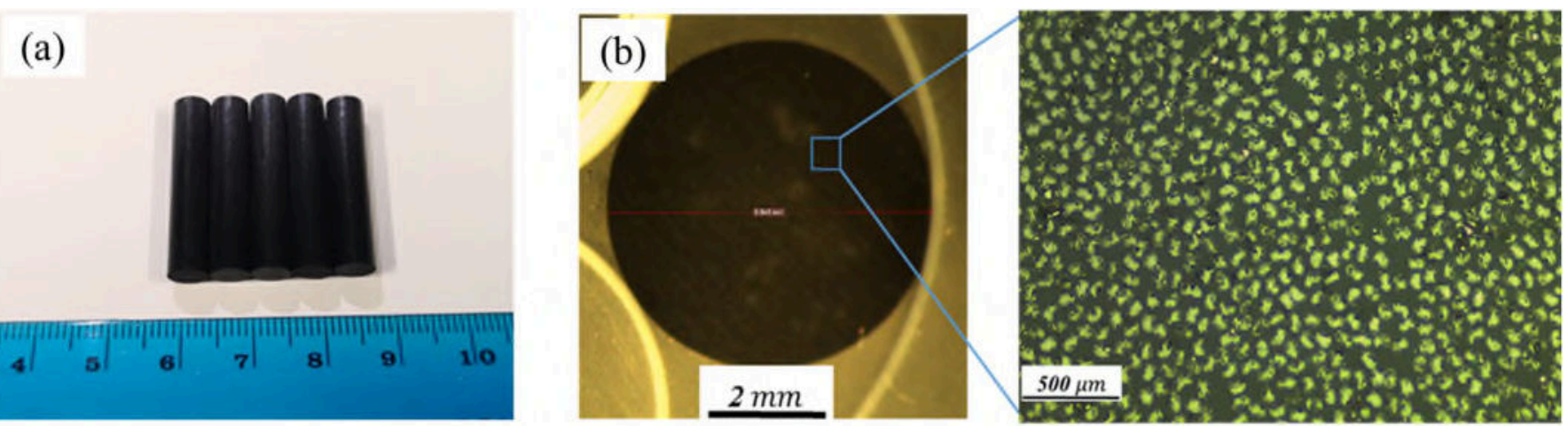

Figure 2: (a) 5mm diameter UD CFRP Pins sample, (b) Cross-section of the CFRP UD Pin

In order to investigate the effect of applying the CFRP Pins on the strength of bonded single-lap joints, the structural performance of the Pins was experimentally investigated in terms of its load bearing performance and associated fracture behaviour. The conducted bearing/shear Pin tests were performed on a single lap joint arrangement using thick steel plates, as shown in figure 3(a). The plates were made of 10mm thick, SM45C steel. The aim of using relatively thick steel plates was to isolate the single lap shear behaviour of the Pins from the secondary bending effects experienced with relatively thinner single lap joint arrangements, as well as to exclude, to the extent possible, the plate hole bearing yield effects. Initial bearing/shear Pin tests performed, indicated local yielding of the steel bearing plates at the bearing hole location in the rim as shown in figure 3(b). This behaviour was expected from compressing carbon fibres against steel, effect that can only be minimized and not completely avoided. The steel material that had plastically poured out of the hole was subsequently trimmed. Following bearing tests did not result in further hole local plastic distortion on the steel plates trimmed holes. That was assumed to be the baseline condition for the plates for 
further testing. In effect, the Pins were loaded in shear with a small offset arising from the surfaces coming into contact.
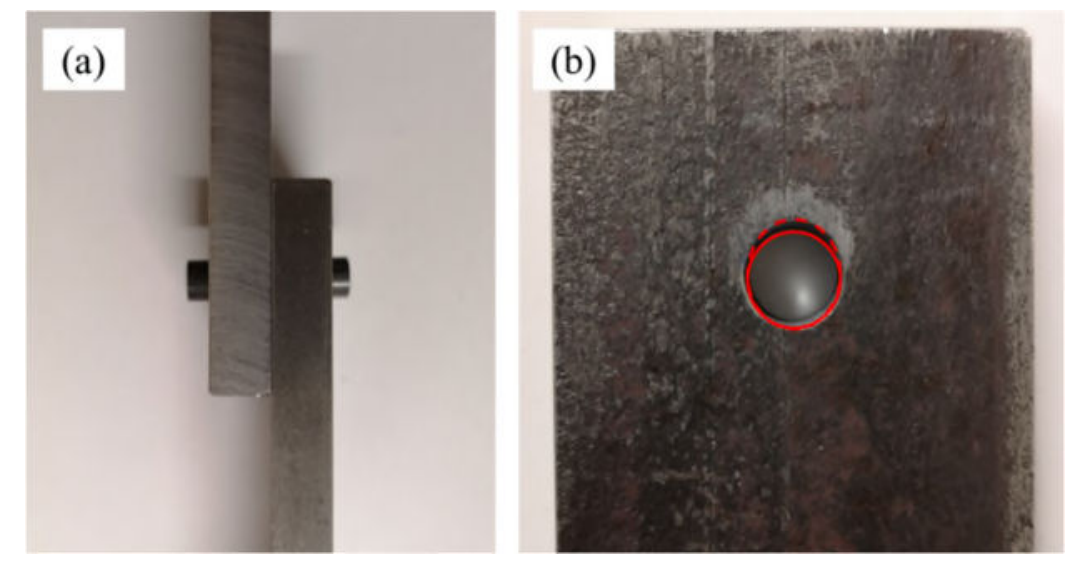

Figure 3: (a) Steel plate single lap joint Bearing/Shear Pin tests, (b) Steel plate filed area, with trimmed of the local yield

Tensile testing was carried out according to ASTM D5961/D5961M-13 [22] on an INSTRON universal testing machine equipped with a $100 \mathrm{kN}$ load cell. The test specimens were loaded at a rate of $1 \mathrm{~mm} / \mathrm{min}$ until final failure, signified by a major drop in the load. Five Pins were tested, three of which were loaded up to failure. The load-displacement curves resulting from the failed specimens are shown in figure 4 . The average failure load for all five specimens was $4.20 \mathrm{kN}$ and the standard deviation was $0.16 \mathrm{kN}$. The maximum and minimum failure loads were $4.56 \mathrm{kN}$ and $4.00 \mathrm{kN}$ respectively.
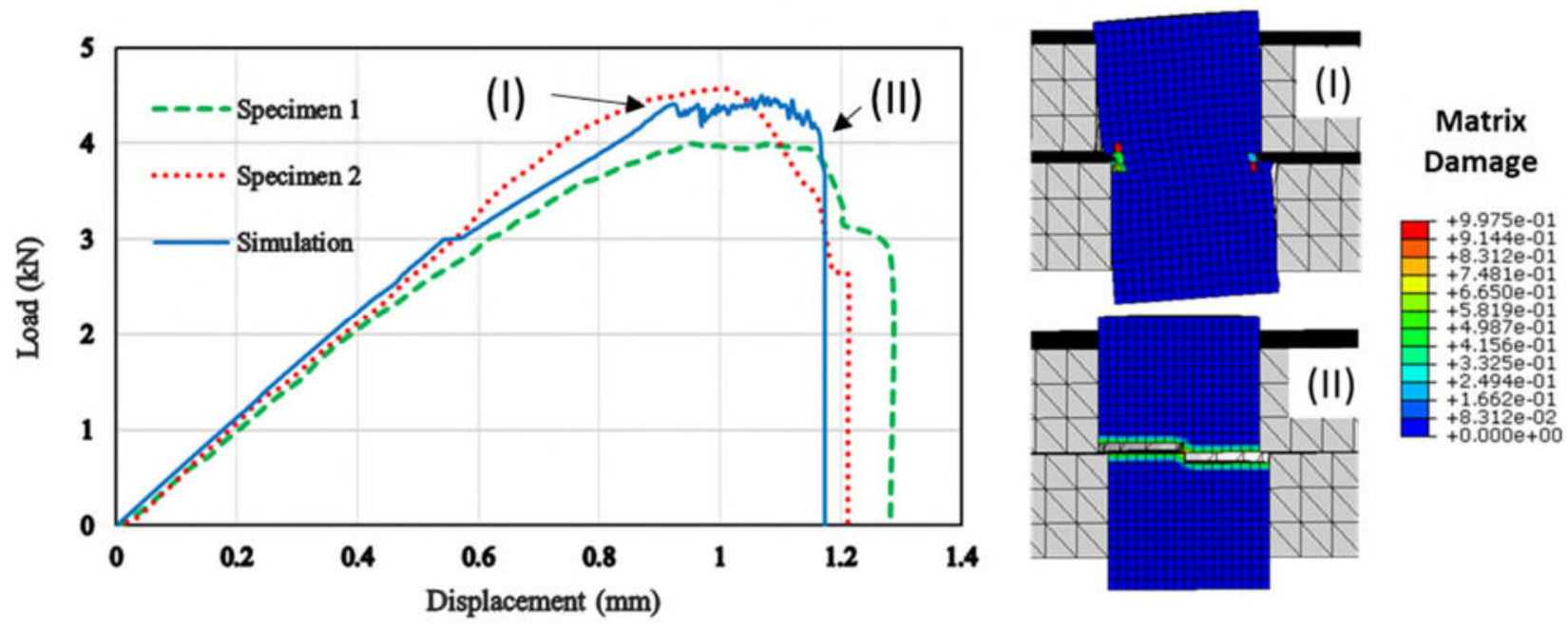

Figure 4: Load-displacement curve of the CFRP Pin in steel plates. Points (I) and (II) on the simulation curve represent the failure initiation and final failure of the Pin. 
Non-linear, progressive damage Finite Element Analysis (FEA) of the bearing/shear Pin tests with the steel plates under single lap joint configuration was conducted, using ABAQUS ${ }^{\circledR} /$ Explicit software. The FE model consisted of the two steel adherents and a composite material Pin, meshed with tetrahedral C3D4 and hexahedral C3D8R elements respectively as shown in figure 4. Experimental tests already performed, apart from the initial steel plate bearing hole local yielding, did not show other signs of failure, therefore the steel lap plates where modelled with homogenous elastic properties, presented in table 1 [23]. The steel plates in the numerical model were offset by an equivalent distance to account for the yielded zone occurring during the initial bearing test. The UD CFRP Pin material properties are tabulated in table 2. The Pin behaviour was modelled using the VUMAT user material interface in ABAQUS ${ }^{\circledR}$, as described in section 2. For capturing the behaviour between the Pin and steel plates, there was a need for updating the contact definition between existing, failed and newly generated bolt-hole surface contact pairs due to the deletion of failed elements. Contact pairs formulation was minimized to avoid unnecessary computational effort. The contact surface between the Pin and two adherents was defined by the surface-to-surface algorithm for higher computational efficiency. For the region where element deletion was allowed, the contact pairs were identified as 'self-contact' under the general contact algorithm in $\mathrm{ABAQUS}^{\circledR}$. Contact pairs formulations, were applied, were using the finite sliding option for both tangential and normal behaviour with a coefficient of friction equal to 0.2 [8]. Numerical results of the Pin bearing simulation showed good agreement with the experiments, as shown in figure 4 . The FE model accurately predicted the non-linear variation in the stiffness from the start of the loading until the maximum load as well as the abrupt load drop. Initially, the composite Pin behaved as a short beam between the two steel plates; Due to the high shearing to bending ratio, the shear stress increased rapidly with increased load application, resulting mainly in matrix cracking at the surface and shear delamination towards the centre of the Pin shown in point 'I' corresponded to figure 5 (a). Some fibre breakage on the surface was evidenced as well. Further load increase past failure initiation, degradation in the stiffness of the Pin was observed, evidenced in the load-displacement curves. Due to the brittle fracture behaviour of the carbon fibre, the composite pin ruptured at the point where the longitudinal stresses reached the failure strength. Most of the pin demonstrated a 'Z-shaped' fractured surface that resulted from the offset shear loading applied on the Pin surface in contact with the steel plates, as shown in point 'II' corresponded to figure 5 (b). The bending moment caused by the offset shear was balanced by the reaction of the surrounding structure due to the tilt of the Pin. The shear mode II fracture behaviour triggered in the Pin, was one of the major energy 
consumption mechanisms during failure, a failure that enhanced the structural toughness and damage tolerance. The numerical simulation strain energy release rate values used, where calibrated by the testing results.

Table 1: Mechanical properties of steel (SM45C)

Young's Modulus (GPa) $\quad$ Yield Strength (MPa) Poisson's ratio $\quad$ Density $\left(\mathrm{g} / \mathrm{cm}^{3}\right)$

$\begin{array}{llll}207 & 370 & 0.30 & 7.60\end{array}$

Table 2: Woven CFRP epoxy lamina and Unidirectional CFRP Pin material properties

\begin{tabular}{|c|c|c|c|c|}
\hline Property & Symbol & Units & CFRP lamina [14] & UD Pin \\
\hline Longitudinal Modulus & $\mathrm{E}_{1}$ & {$[\mathrm{GPa}]$} & 49.8 & 40 \\
\hline Transverse Modulus & $\mathrm{E}_{2}$ & [GPa] & 49.8 & 12 \\
\hline Shear Modulus & $\mathrm{G}_{12}$ & [GPa $]$ & 4.56 & 4 \\
\hline Poisson's ratio & $\mathrm{V}_{12}$ & {$[-]$} & 0.05 & 0.32 \\
\hline Long. tension Strength & $\mathrm{X}_{\mathrm{t}}$ & {$[\mathrm{MPa}]$} & 621.5 & 500 \\
\hline Trans. Tension Strength & $Y_{t}$ & {$[\mathrm{MPa}]$} & 621.5 & 30 \\
\hline Long. compression Strength & $\mathrm{X}_{\mathrm{c}}$ & {$[\mathrm{MPa}]$} & 495.6 & 320 \\
\hline Trans. compression Strength & $\mathrm{Y}_{\mathrm{c}}$ & {$[\mathrm{MPa}]$} & 495.6 & 100 \\
\hline Shear Strength & S & {$[\mathrm{MPa}]$} & 99.16 & 40 \\
\hline $\begin{array}{l}\text { Fibre fracture SERR* } \\
\text { (tension) }\end{array}$ & $\mathrm{G}^{\mathrm{c}}{ }_{1+,} \mathrm{G}^{\mathrm{c}}{ }_{2+}$ & {$[\mathrm{N} / \mathrm{mm}]$} & 44.9 & 100,5 \\
\hline $\begin{array}{l}\text { Fibre fracture SERR* } \\
\text { (compression) }\end{array}$ & $\mathrm{G}_{1-,}^{\mathrm{c}} \mathrm{G}_{2-}^{\mathrm{c}}$ & {$[\mathrm{N} / \mathrm{mm}]$} & 39.15 & 100,5 \\
\hline
\end{tabular}

*SERR: Strain Energy Release Rate or Fracture Toughness 

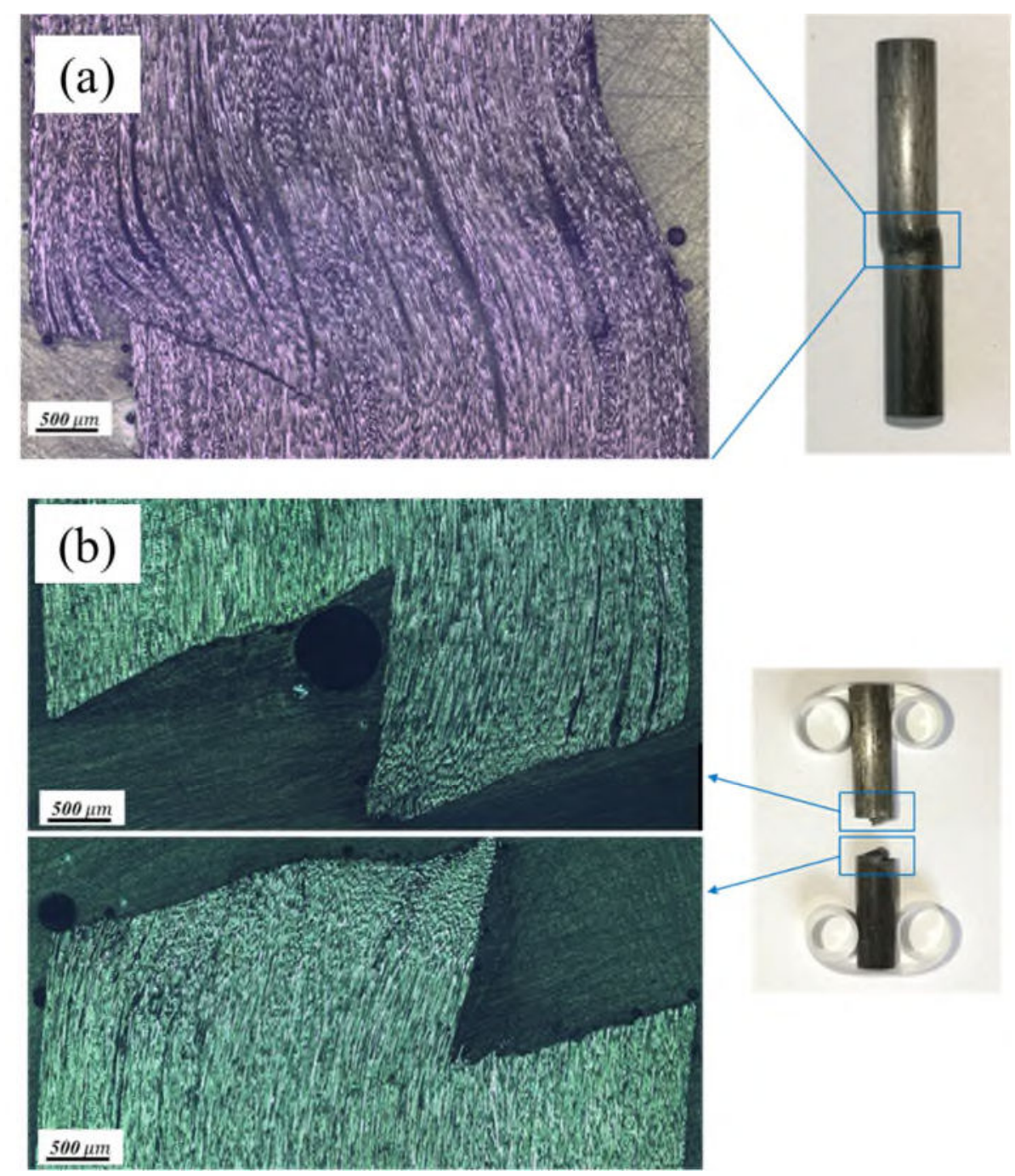

Figure 5: Fractured specimen (a) at failure initiation corresponding point 'I' (b) after testing corresponding point 'II' under microscope observation

\section{Bonded and hybrid bonded/pinned joints}

To test the effects of the application of the UD CFRP Pins upon adhesively bonded joints, eight Single Lap Joint (SLJ) specimens were manufactured, three of which were bonded, and the rest were bonded and reinforced by composite Pins, thus producing the hybrid single lap joint. The geometry of the hybrid SLJ specimen design is displayed in figure 6, whilst an identical design was followed for the plain bonded SLJ, by omitting the Pin. The lap plate adherents were made of woven CFRP material with properties shown on table 2 . The laminates consisted of nine lamina layers were arranged in a stacking sequence of $\left[45^{\circ} / 0^{\circ} / 45^{\circ} / 0^{\circ} / 45^{\circ} / 0^{\circ} / 45^{\circ} / 0^{\circ} / 45^{\circ}\right]_{\mathrm{s}}$, where the $45^{\circ}$ and $0^{\circ}$ direction represented a single woven 
fibre laminate in $\left[+45^{\circ} /-45^{\circ}\right]$ and $\left[0^{\circ} / 90^{\circ}\right]$ directions respectively. The overall thickness of the cured adherent was $3.24 \mathrm{~mm}$. Two-component epoxy Redux $420^{\circledR}$ adhesive was used to bond the two adherents together, with an overlap splice length of $40 \mathrm{~mm}$. Following the adherent bonding process, holes of $5 \mathrm{~mm}$ diameter were drilled at the centre of the bonded overlap region using a dagger drill. Subsequently, the $5 \mathrm{~mm}$ diameter composite Pin rods of $10 \mathrm{~mm}$ in length were inserted in the holes. The Pins were not cut exactly at a length to match the total lap plate thickness of the joint. It is anticipated, although not experimentally proven, that Pins installed flush in a lap joint, will not enhance the joint strength to the extents a prodding Pin is. At the specimen grips, doublers made from the same material and layup sequence were bonded to minimise eccentricity along with aluminium end tabs of $0.2 \mathrm{~mm}$ thickness. Tensile bearing tests were performed until final failure of the specimens, on the same machine and loading parameters dictated in the previous section.

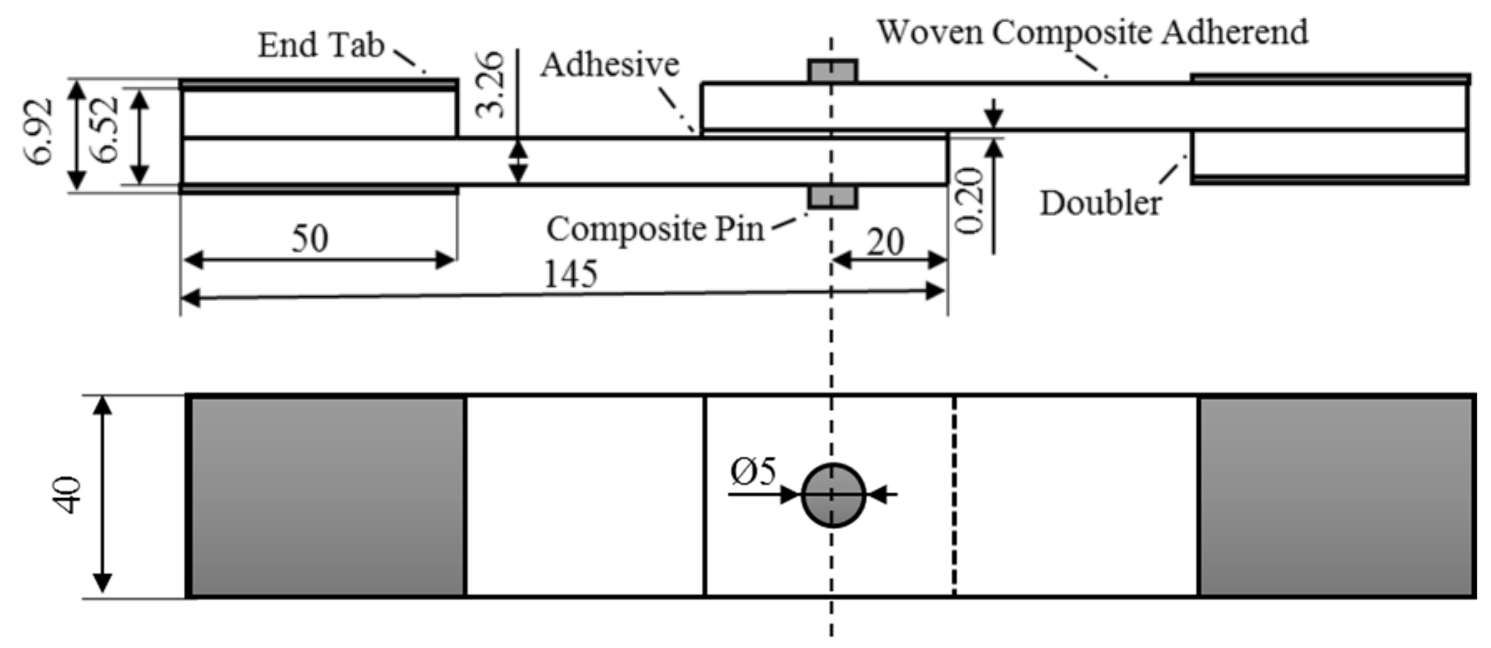

Figure 6: Geometry of the hybrid bonded/Pinned SLJ

Alongside the experimental survey, non-linear progressive damage numerical FEA models were composed for calibration and validation. Half symmetric, three-dimensional finite element numerical models of the bonded SLJ and the hybrid SLJ were generated in ABAQUS ${ }^{\circledR} /$ Explicit, the latter is shown in figure 7 . The hybrid joint model comprised of the composite adherents, the adhesive layer and the composite material Pin. The adherents and the Pin where assumed to be orthotropic materials. Three-dimensional 8-node linear hexahedral elements C3D8R with hourglass control were used for both the adherents and Pin. In the vicinity of the bond region, three-dimensional, hexahedral cohesive elements COH3D8 were 
employed for modelling the adhesive bond as well as the last adherent layer interfaces closest to the bond on either side. A single row of cohesive elements of $0.2 \mathrm{~mm}$ thickness modelled the overlap bond region. One element per ply was used along the adhered thickness, whilst two layers of zero-thickness layers of cohesive elements modelled the two lamina interfaces adjacent to the adhesive bond. The cohesive element size was one-sixth in size compared to the solid elements size.

The tensile and compressive properties of the woven fabric were measured based on the ASTM D3039 [24] and ASTM D6641 [25] experimental procedures. The remaining material properties shown in table 2 were read from reference [26], were the same material under the same curing procedure was used. The damage model for composite rods and adherents with refined mesh was implemented in ABAQUS ${ }^{\circledR} /$ Explicit through the VUMAT, user material subroutine, as explained before. The numerical parameters for the adhesive and woven fabric interlaminar locations, are summarized in table 3. The parameters for the Redux $420^{\circledR}$ adhesive were read from references [27], [28].

Boundary conditions included fixing the joints at one of the edges, to replicate the testing machine gripping, while the opposite edge was subjected to external load together with the other two directions restraining.

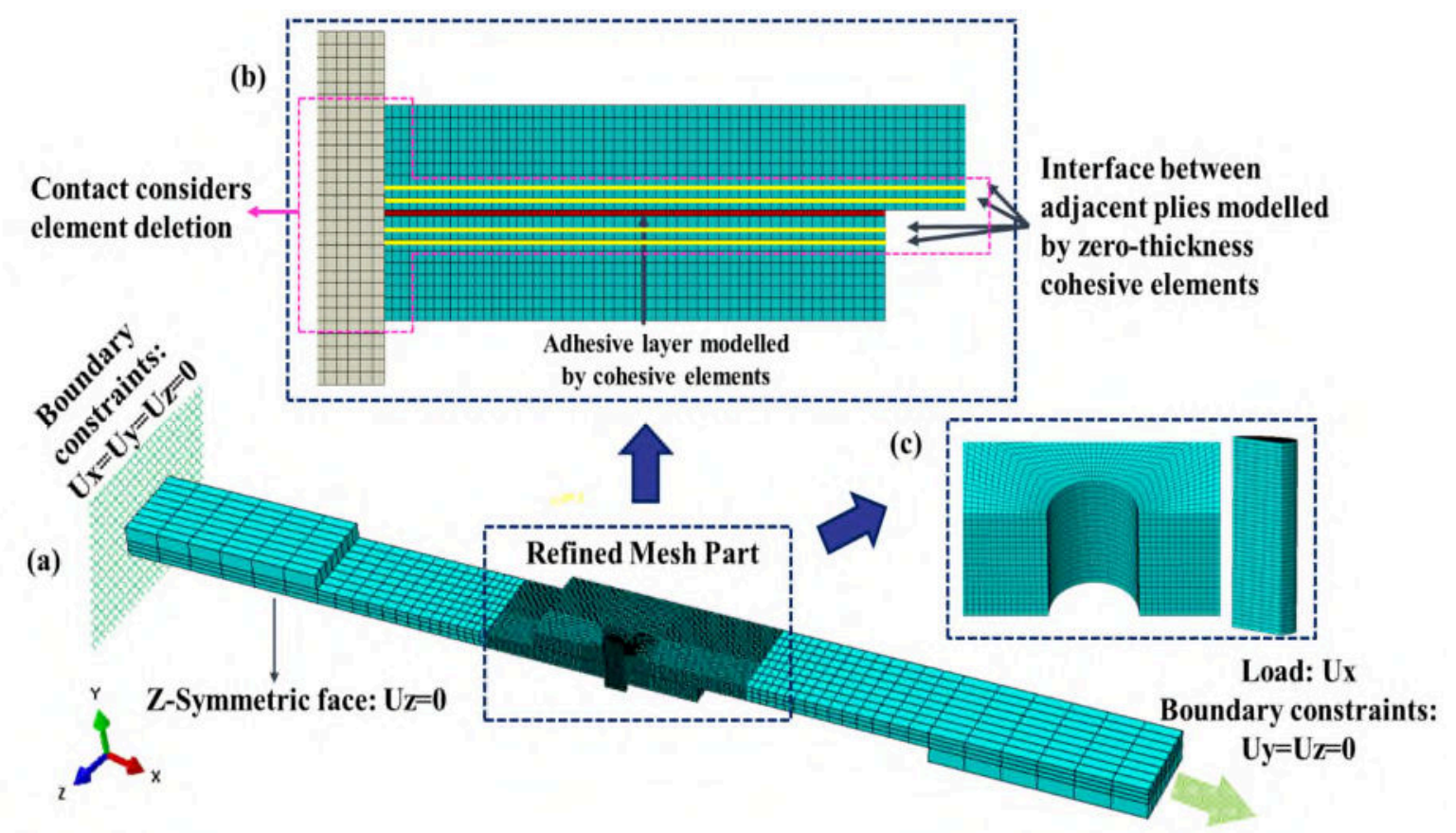

Figure 7: (a) FE model and loading conditions of the hybrid joint, (b) cohesive layers and contact area (c) Pin and annular area 
Table 3: Cohesive zone model parameters

\begin{tabular}{ccccc} 
Property & Symbol & Units & $\begin{array}{c}\text { Adhesive } \\
\text { Redux420 }^{\circledR}\end{array}$ & $\begin{array}{c}\text { CFRP } \\
\text { Interlaminar }\end{array}$ \\
\hline Penalty Stiffness / normal direction & $\mathrm{K}_{\mathrm{n}}$ & {$[\mathrm{MPa}]$} & 10,000 & 10,000 \\
Penalty Stiffness / shear direction & $\mathrm{K}_{\mathrm{s}}$ & {$[\mathrm{MPa}]$} & 10,000 & 10,000 \\
Traction Strength / normal direction & $\mathrm{t}_{\mathrm{n}}$ & {$[\mathrm{MPa}]$} & $38.32[27]$ & 30 \\
Traction Strength / shear direction & $\mathrm{t}_{\mathrm{s}}$ & {$[\mathrm{MPa}]$} & $28.92[27]$ & 20 \\
SERR* / normal direction & $\mathrm{G}_{\mathrm{n}}^{\mathrm{c}}$ & {$[\mathrm{N} / \mathrm{mm}]$} & $1.26[28]$ & 1 \\
SERR* / shear direction & $\mathrm{G}_{\mathrm{s}}^{\mathrm{c}}$ & {$[\mathrm{N} / \mathrm{mm}]$} & $4.12[28]$ & 2.5 \\
\hline
\end{tabular}

*SERR: Strain Energy Release Rate or Fracture Toughness

\section{Results and discussion}

Representative load-displacement curves from the tensile tests for the plainly bonded and hybrid joints are shown in figure 8 , along with the FEA simulation results. On the same chart, the Pin standalone tensile test using the steel plates is shown for comparison.

For the plain bonded joints, the measured average and standard deviation of maximum load was $32 \mathrm{kN}$ and $1.56 \mathrm{kN}$, respectively, based on three tests. The FE model results were in good agreement with the experiments. The slight deviation in the stiffness observed between the FEA models and experiments before the load drop is attributed to the numerical model clamp boundary condition which overestimated the clamping force. During testing, all specimens failed in a mixed type of delamination failure, where adherent and adhesive failure were partly experienced, as shown in figure 9. The fact that interlaminar delamination was one of the failure modes in the adherents, suggested that a good bonding quality was achieved at the adherent bonding interface. The failure process of the bonded SLJ was quite effectively reproduced by the FE model. 


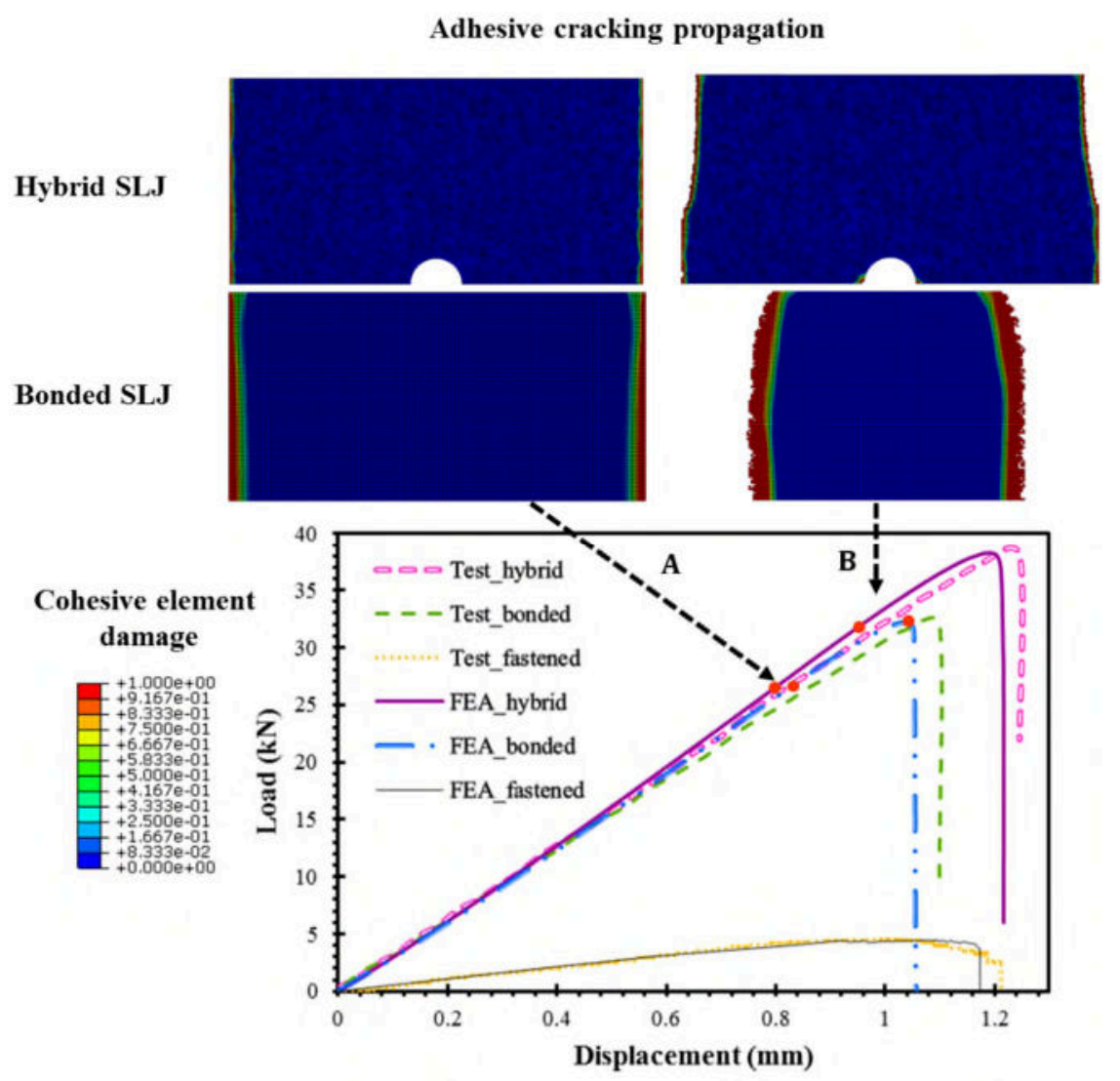

Figure 8: Load vs displacement curves and adhesive crack propagation at load A and B.

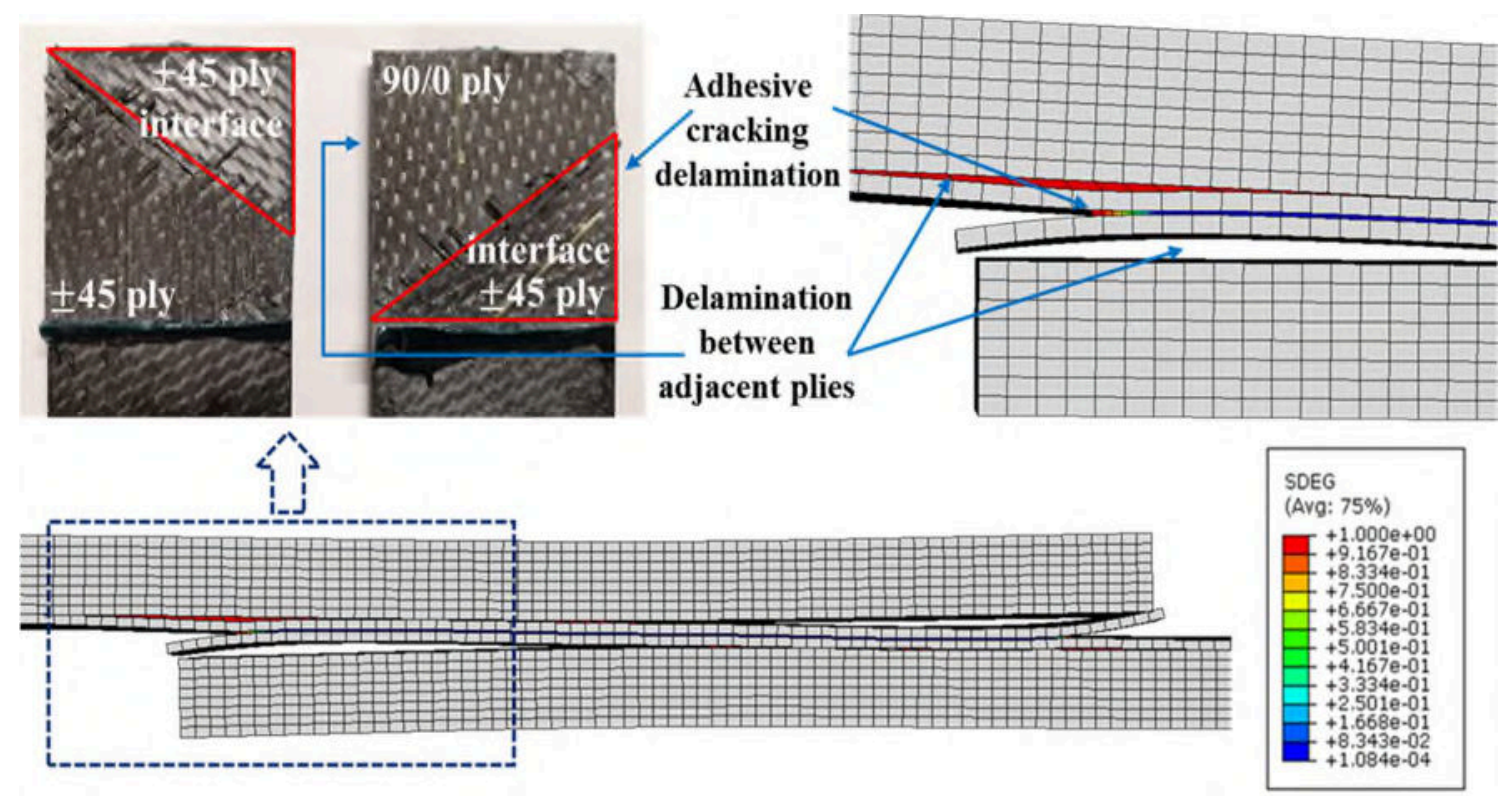

Figure 9: Bonded joint failure mode simulation vs experiment 
The hybrid bonded/pinned joints demonstrated equal stiffness to the bonded specimen at loading levels prior to bond failure. The structural stiffness of the hybrid joint was not altered by Pin, since at the early stages of loading, specimen stiffness is driven by the adherent specimen length, fabric properties and layup. The adhesive layer itself which spans for $40 \mathrm{~mm}$ is a very stiff part of the joint assembly and prior to bond damage initiation, load flows through it, bypassing the Pin. However, at load level greater than $15 \mathrm{kN}$, the hybrid joint demonstrated steeper slope and a higher ultimate failure load. There was some variability in the measured failure load based on the tests performed on the five samples. The average value for the ultimate load was $38.1 \mathrm{kN}$ and the standard deviation was $2.44 \mathrm{kN}$, about $6.4 \%$ of the average value. Reinforcing the composite pin into the bonded joint achieved $19.1 \%$ improvement in the ultimate failure load with respect the bonded joint, based on the test measurements. The numerical analysis predicted that the introduction of composite Pin increase the failure resistance and damage tolerance, generating a cracking arrest effect as shown in figure 8 from point A to B. Numerical analysis predicted the experimentally measured load-displacement curves. The damage model was able to predict the initial stiffness and subsequent stiffness variation of the joints quite accurately. The experimental tested and numerical analysis predicted ultimate failure load is summarized in figure 10.

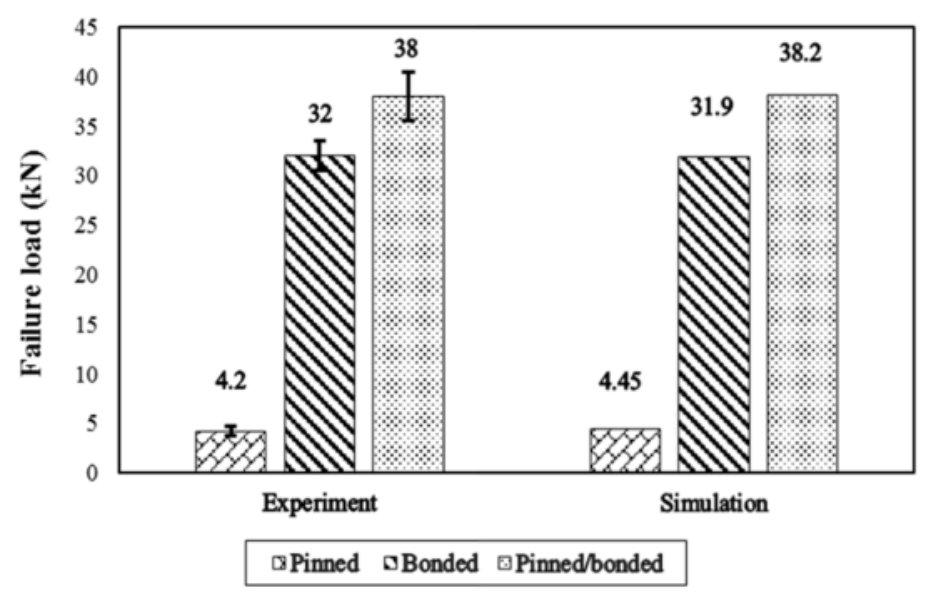

Figure 10: Failure loads for the single-lap joints in tension

Figure 11 (a), depicts the failure mode of the hybrid joint as experienced during testing, similar to the failure mode in the bonded joints. All specimens showed delamination propagating in the adherents in the form of interlaminar delamination, with the adhesive bond being able to sustain the load. Numerical modelling predicted failure contour in the lower 
adherent of the joint after final failure is plotted in figure 11 (b), caused by the adherent warp and tilted pin. The thinner and more flexible composite adherent, with respect the steel plates, introduced secondary bending effects that resulted in the damage shown. The damaged hole reduced the stress concentration level on the Pin, which led to bypassing the fracture failure of the composite Pin, evidenced in both simulation and test. Approaching the ultimate joint failure level, the delaminated lap joint with the damaged bearing hole, provided with increased secondary bending flexibility to the joint and due to the absence of a fastener head, the Pin slided out of the hole and the joint failed.

(a)

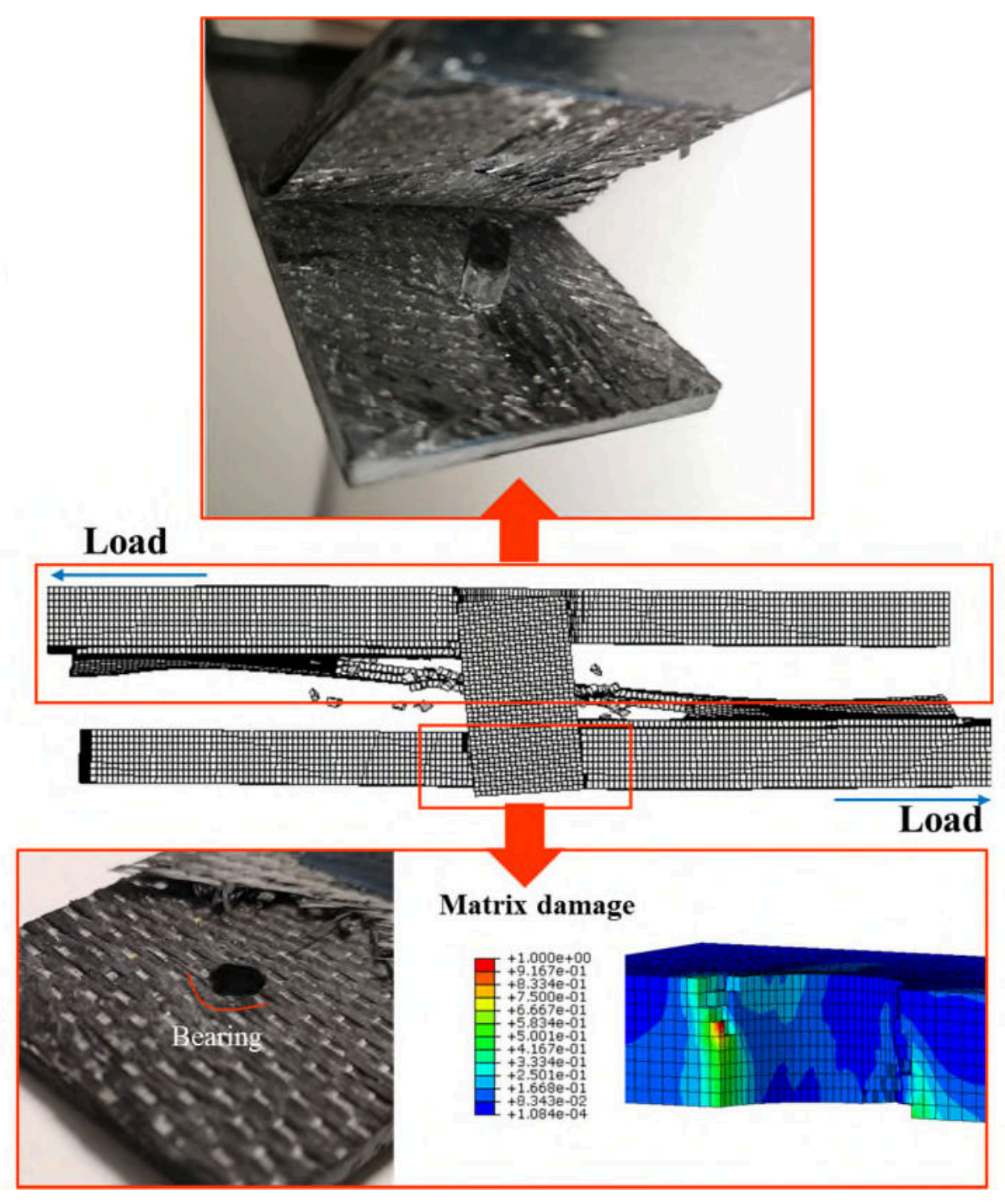

Figure 11: Hybrid joint failure mode simulation vs experiment

In order to quantify the load sharing between the Pin and the adhesive in the postadhesive failure region, the load transferred by the Pin was numerically evaluated by summing 
the shear nodal forces on the adjacent adhesive cross surface. In figure 12, the load transferred by Pin is plotted against total load on the specimen is shown. The load transferred increased linearly with the applied load during the initial stage. For higher externally applied loading levels, the rate of force transfer against applied load decreased with increased applied load. At ultimate joint failure, the composite Pin carried $13.6 \%$ of the applied load.

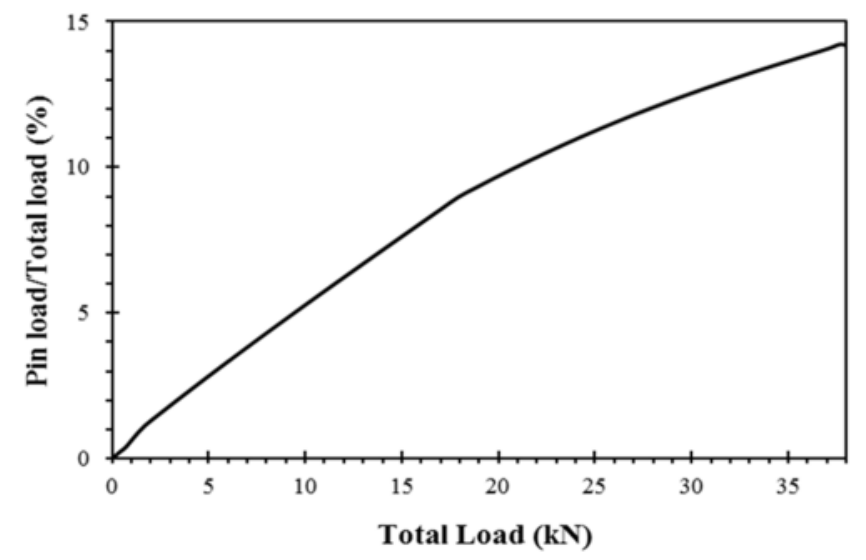

Figure 12: Numerically predicted percentage of load transfer by the Pin in the hybrid joint

The numerical model was queried with regard to the stresses in the bond overlap region. In figure 13 , the shear stress $\left(\tau_{x y}\right)$ and peel stress $\left(\sigma_{y y}\right)$ distribution along the bond line of the joint at centre position in width at pre-defined load of $20 \mathrm{kN}$ are plotted. The shear stress distribution along the length of the overlap is shown in figure 13 (a). The hybrid joint exhibited lower peak shear stress close to the tips and slightly lower towards the centre of the overlap length, evidence of load sharing between the Pin and adhesive. The peel stress distribution along the length of the overlap is shown in figure 13 (b). The Pin was shown to reduce the magnitude of the maximum peel stresses at the ends of the bond. This was attributed to the Pin increasing the out-of-plane bending stiffness, which limited the secondary bending and further increased of the joint strength. 


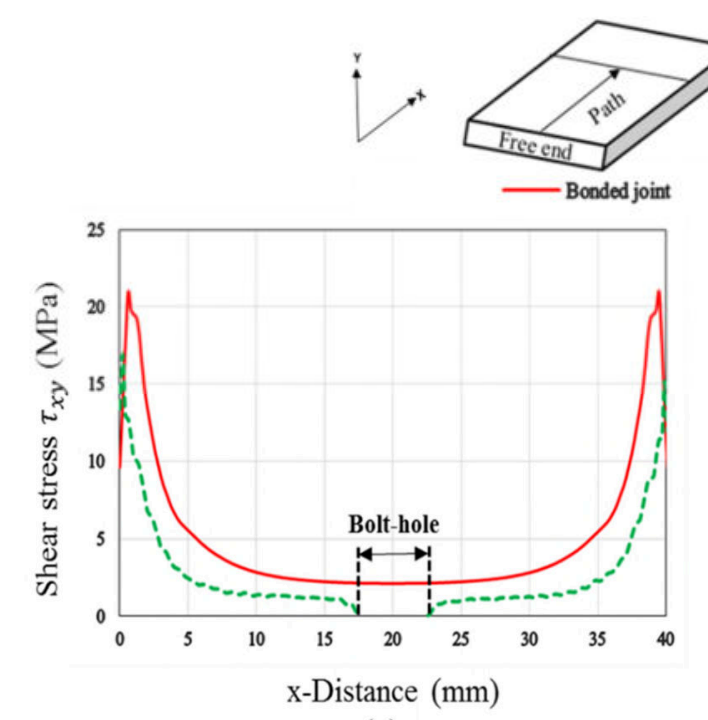

(a)
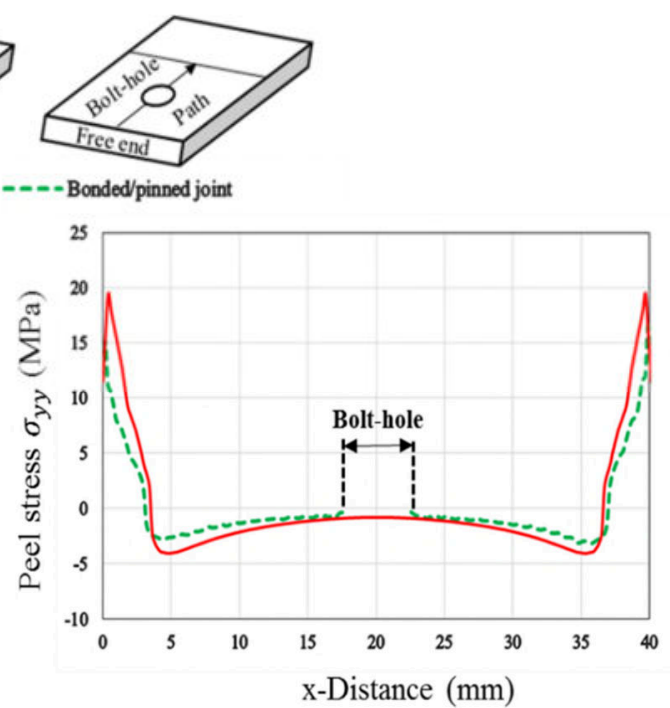

(b)

Figure 13: Shear and peel stresses distribution comparison in bonded and hybrid bonded/Pinned joints at tensile load $\mathrm{P}=20 \mathrm{kN}$

\section{Numerical parametric study}

A numerical study on SLJs reinforced by steel Pins was conducted for comparison to the ones with the CFRP Pin based on similar pin diameters. Pins made out of SM45C steel were employed, with material properties given in table 1 . The numerical study was further extended to analyse the effect of different diameters and fibre orientations of the CFRP Pin on the failure strength of single-lap joint. The summary of the results are shown on table 4 and figure 14. For the unidirectional CFRP Pin, with increasing diameter from $5 \mathrm{~mm}$ to $8 \mathrm{~mm}$, the joint failure load increase by $10 \%$, increase which was mainly attributed to the increased load shearing between the pin and the adhesive. Numerical analysis predicted that $18.3 \%$ of the load transferred by the $8 \mathrm{~mm}$ CFRP Pin, while $14.2 \%$ was expected for the $5 \mathrm{~mm}$ diameter Pin at maximum joint loading. By replacing the 5mm CFRP Pin with an $8 \mathrm{~mm}$ one, the out-of-plane stiffness of the hybrid joints increases which reduces the secondary bending and further delay the delamination cracking propagation. The failure load for the 8mm CFRP Pinned hybrid joint is only $2.1 \%$ lower than for the joint reinforced by a $5 \mathrm{~mm}$ steel Pin at a weight reduction of $46.9 \%$. It is important to note that the $8 \mathrm{~mm}$ hybrid joint with the CFRP Pin, had a fastening hole with an cross sectional area of about $3.1 \%$ of total the bonded area, while the $5 \mathrm{~mm}$ steel Hybrid joint is only $1.2 \%$ of the total bond area. Although the $8 \mathrm{~mm}$ CFRP Pin can potentially transfer a higher load compared to $5 \mathrm{~mm}$ steel pin though the Pin itself, the reduced bonding 
area lead to reduced failure load for the joint. Furthermore, to further improve the specific strength of the joint, the CFRP Pin could be optimised by varying the carbon fibre orientation for improving the Pin shear modulus. For example, by using $\pm 45^{\circ}$ oriented fibres, an $8 \mathrm{~mm}$ CFRP Pin could potentially improve the joint failure load to $43.2 \mathrm{kN}$, according to the numerical simulations, while retaining the weight reduction and corrosion enhancement benefit.

Table 4: Pin failure load and weight for various diameters and fibre orientations

\begin{tabular}{cccc}
$\begin{array}{c}\text { Pin diameter }(\mathbf{m m}) \\
\text { (fibre orientation) }\end{array}$ & $\begin{array}{c}\text { Failure Load } \\
(\mathbf{k N})\end{array}$ & Weight of pin $(\mathbf{g})$ & $\begin{array}{c}\text { Maximum load } \\
\text { transferred by pin }\end{array}$ \\
\hline $\mathrm{D}=5\left(0^{0}\right)$ & 38.1 & 0.3 & $14.2 \%$ \\
$\mathrm{D}=6\left(0^{0}\right)$ & 39.4 & 0.4 & $15.9 \%$ \\
$\mathrm{D}=8\left(0^{0}\right)$ & 41.9 & 0.8 & $18.6 \%$ \\
$\mathrm{D}=8\left( \pm 45^{0}\right)$ & 43.2 & 0.8 & $22.1 \%$ \\
\hline Steel $\mathrm{D}=5$ & 42.8 & 1.5 & $17.8 \%$
\end{tabular}

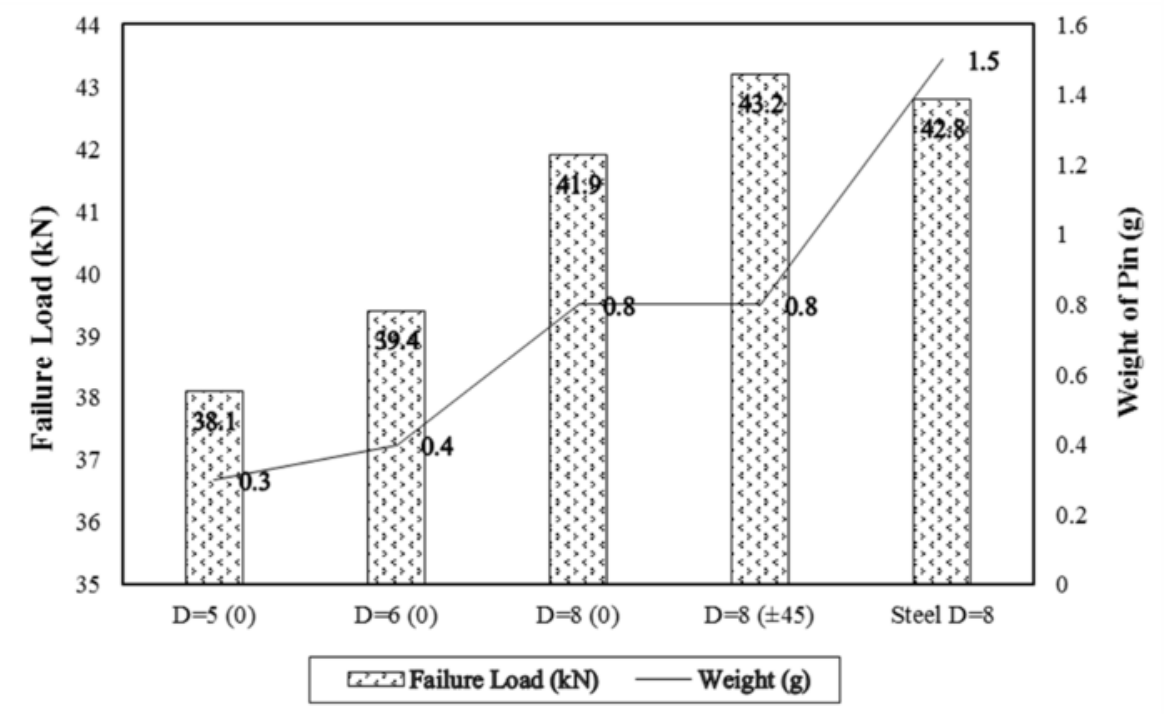

Figure 14: Hybrid joint failure load and Pin weight for Pins according to table 4 


\section{Conclusions}

In this study, the enhanced strength of a hybrid adhesively bonded/Pinned joint using a composite material Pin was investigated. The structural benefits of this hybrid joint emerge in the post adhesive failure initiation region. A combination of experimental and numerical methods was utilized to investigate the failure load and failure modes of the plain adhesively bonded and the hybrid bonded/Pinned single lap joints. Following the numerical modelling verification, various numerical parametric studies were performed; one of them compared the hybrid joint failure modes with a supposed hybrid joint reinforced forced by a steel Pin; the others numerically analysed the effect of the composite Pin diameter and possible change in the fibre orientation upon the failure load of the hybrid joint. The results obtained in this work are summarized as follows:

- Reinforcing the bonded SLJ with a CFRP Pin resulted in a $19.1 \%$ increase in the ultimate failure load under static tension loading.

- The hybrid joint strength enhancement resulted from the load sharing between the Pin and adhesive and from the increase in the out-of-plane bending stiffness, which alleviated the peel stresses in the adhesive bond.

- The numerical CDM proposed, predicted the experimentally derived failure load with a good accuracy.

- By increasing the Pin diameter and possibly rearranging the fibre orientation on the Pin, the hybrid joint could potentially achieve an even higher failure load.

\section{Acknowledge:}

The authors acknowledge the financial support from China Scholarship Council (CSC NO. 201708140099). 


\section{References:}

[1] K. Bodjona, K. Raju, G.-H. Lim, and L. Lessard, "Load sharing in single-lap bonded/bolted composite joints. Part I: Model development and validation," Compos. Struct., vol. 129, pp. 268-275, 2015.

[2] K. Bodjona and L. Lessard, "Load sharing in single-lap bonded/bolted composite joints. Part II: Global sensitivity analysis," Compos. Struct., vol. 129, pp. 276-283, 2015.

[3] S. W. Kandebo, "Super Hornet cost reductions could boost export potential," Aviat. Week Space Technol., vol. 152, no. 15, p. 58, 2000.

[4] R. T. Cole, E. J. Bateh, and J. Potter, "Fasteners for composite structures," Composites, vol. 13, no. 3, pp. 233-240, 1982.

[5] M. Stewart and M. Stewart, "An experimental investigation of composite bonded and/or bolted repairs using single lap joint designs," in 38th Structures, Structural Dynamics, and Materials Conference, 1997, p. 1339.

[6] G. Kelly, "Load transfer in hybrid (bonded/bolted) composite single-lap joints," Compos. Struct., vol. 69, no. 1, pp. 35-43, 2005.

[7] J. H. Kweon, J. W. Jung, T. H. Kim, J. H. Choi, and D. H. Kim, "Failure of carbon composite-to-aluminum joints with combined mechanical fastening and adhesive bonding," Compos. Struct., vol. 75, no. 1-4, pp. 192-198, 2006.

[8] G. Kelly, "Quasi-static strength and fatigue life of hybrid (bonded/bolted) composite single-lap joints,” Compos. Struct., vol. 72, no. 1, pp. 119-129, 2006.

[9] R. Matsuzaki, M. Shibata, and A. Todoroki, "Improving performance of GFRP/aluminum single lap joints using bolted/co-cured hybrid method," Compos. Part A Appl. Sci. Manuf., vol. 39, no. 2, pp. 154-163, 2008.

[10] S. D. Thoppul, J. Finegan, and R. F. Gibson, "Mechanics of mechanically fastened joints in polymer-matrix composite structures-a review," Compos. Sci. Technol., vol. 69, no. 3-4, pp. 301-329, 2009.

[11] R. Starikov and J. Schön, "Quasi-static behaviour of composite joints with countersunk composite and metal fasteners," Compos. Part B Eng., vol. 32, no. 5, pp. 401-411, 2001.

[12] R. Starikov and J. Schön, "Fatigue resistance of composite joints with countersunk composite and metal fasteners," Int. J. Fatigue, vol. 24, no. 1, pp. 39-47, 2002.

[13] M. Ueda, N. Ui, and A. Ohtani, "Lightweight and anti-corrosive fiber reinforced thermoplastic rivet," Compos. Struct., vol. 188, pp. 356-362, 2018.

[14] G. Z. Voyiadjis and P. I. Kattan, "A plasticity-damage theory for large deformation of solids-I. Theoretical formulation," Int. J. Eng. Sci., vol. 30, no. 9, pp. 1089-1108, 1992.

[15] G. Voyiadjis, Advances in damage mechanics: metals and metal matrix composites. Elsevier, 2012.

[16] L. Jia et al., "Combined modelling and experimental studies of failure in thick laminates 
under out-of-plane shear," Compos. Part B Eng., vol. 105, pp. 8-22, 2016.

[17] Z. Hashin and A. Rotem, "A fatigue failure criterion for fiber reinforced materials," $J$. Compos. Mater., vol. 7, no. 4, pp. 448-464, 1973.

[18] S. T. Pinho, L. Iannucci, and P. Robinson, "Physically-based failure models and criteria for laminated fibre-reinforced composites with emphasis on fibre kinking: Part I: Development," vol. 37, pp. 63-73, 2006.

[19] S. T. Pinho, L. Iannucci, P. Robinson, P. P. Camanho, and C. G. Da, "Prediction of in situ strengths and matrix cracking in composites under transverse tension and in-plane shear," vol. 37, pp. 165-176, 2006.

[20] S. T. Pinho, C. G. Dávila, P. P. Camanho, L. Iannucci, and P. Robinson, "Failure Models and Criteria for FRP Under In-Plane or Three-Dimensional Stress States Including Shear Non-Linearity," no. February, 2005.

[21] M. L. Benzeggagh and M. Kenane, "Measurement of mixed-mode delamination fracture toughness of unidirectional glass/epoxy composites with mixed-mode bending apparatus," Compos. Sci. Technol., vol. 56, no. 4, pp. 439-449, 1996.

[22] M. H. Song, J. H. Kweon, and S. K. Kim, "Standard test method for bearing response of polymer matrix composite lami nates." West Conshohocken, PA: ASTM International, 2005.

[23] T. Rangaswamy and S. Vijayrangan, "Optimal sizing and stacking sequence of composite drive shafts," Mater. sci, vol. 11, 2005.

[24] A. C. D.-30 on C. Materials, Standard test method for tensile properties of polymer matrix composite materials. ASTM International, 2008.

[25] A. Standard, "D6641/D6641M-14," Stand. Test Method Compressive Prop. Polym. Matrix Compos. Mater. Using a Comb. Load. Compression Test Fixture. ASTM Int. W Conshohocken, 2014.

[26] X. F. Hu, A. Haris, M. Ridha, V. B. C. Tan, and T. E. Tay, "Progressive failure of bolted single-lap joints of woven fibre-reinforced composites," Compos. Struct., vol. 189, pp. 443-454, 2018.

[27] J.-Y. Cognard, P. Davies, L. Sohier, and R. Créac'hcadec, "A study of the non-linear behaviour of adhesively-bonded composite assemblies," Compos. Struct., vol. 76, no. 1-2, pp. 34-46, 2006.

[28] J. P. SARGENT and P. DAVIES, "ADHESIVE JOINT STRENGTH PREDICTION FOR COMPOSITE DESIGN," Appl. Fract. Mech. to Polym. Adhes. Compos., vol. 33, p. 157, 2003. 
2020-01-10

\title{
Strength enhancement of bonded
} composite laminate joints reinforced by composite pins

\author{
$\mathrm{Li}$, Wenhao
}

Elsevier

Li W, Guo S, Giannopoulos IK, et al., (2020) Strength enhancement of bonded composite laminate joints reinforced by composite pins. Composite Structures, Volume 236, March 2020, Article number 111916

https://doi.org/10.1016/j.compstruct.2020.111916

Downloaded from Cranfield Library Services E-Repository 